\title{
Enhancing color quality of WLEDs with dual-layer remote phosphor geometry
}

\author{
Phung Ton That ${ }^{1}$, Nguyen Thi Phuong LoAn ${ }^{2}$, Le VAn Tho $^{3}$, \\ Nguyen DoAn Quoc AnH ${ }^{4, *}$, Hsing-YuAn LiaO ${ }^{5}$, Guo-Feng Luo ${ }^{5}$, HsiaO-Yi LeE ${ }^{5}$ \\ ${ }^{1}$ Faculty of Electronics Technology, Industrial University of Ho Chi Minh City, Ho Chi Minh City, Vietnam \\ ${ }^{2}$ Faculty of Fundamental 2, Posts and Telecommunications Institute of Technology, Ho Chi Minh City, Vietnam \\ ${ }^{3}$ Institute of Tropical Biology, Vietnam Academy of Science and Technology, Ho Chi Minh City, Vietnam \\ ${ }^{4}$ Faculty of Electrical and Electronics Engineering, Ton Duc Thang University, Ho Chi Minh City, Vietnam \\ ${ }^{5}$ Department of Electrical Engineering, National Kaohsiung University of Science and Technology, Kaohsiung, Taiwan
}

\begin{abstract}
Usually, remote phosphor structures are beneficial in terms of flux but unfavorable in terms of color quality compared to conformal phosphor or in-cup phosphor packages. To eliminate this disadvantage, many studies have focused on increasing the chromatic quality of the remote phosphor configuration, which requires great efforts in improving two parameters of color: color rendering index (CRI) and color quality scale (CQS). CRI is known as the most useful quantitative method used to measure the ability of a light source to reproduce the colors of illuminated objects faithfully and naturally. Similarly, CQS is also a method of lighting quality determination and analysis, especially used as an alternative to the unsaturated CRI colors. In this paper, we proposed dual-layer remote phosphor structure as a novel method of CRI and CQS enhancement to improve WLEDs' color quality. Five alike WLEDs but having different color temperatures in the range of $5600 \mathrm{~K}$ to $8500 \mathrm{~K}$ were applied in this study. The idea behind the study is to place a red phosphor layer $\mathrm{Sr}_{\mathrm{w}} \mathrm{F}_{\mathrm{x}} \mathrm{B}_{\mathrm{y}} \mathrm{O}_{\mathrm{z}}: \mathrm{Eu}^{2+}, \mathrm{Sm}^{2+}$ on the yellow phosphor layer YAG: $\mathrm{Ce}^{3+}$ and then determining an appropriate concentration of $\mathrm{Sr}_{\mathrm{w}} \mathrm{F}_{\mathrm{x}} \mathrm{B}_{\mathrm{y}} \mathrm{O}_{\mathrm{z}}: \mathrm{Eu}^{2+}, \mathrm{Sm}^{2+}$ added to achieve the highest color quality. The results point out that $\mathrm{Sr}_{\mathrm{w}} \mathrm{F}_{\mathrm{x}} \mathrm{B}_{\mathrm{y}} \mathrm{O}_{\mathrm{z}}: \mathrm{Eu}^{2+}, \mathrm{Sm}^{2+}$ brings great benefits to the improvement of CRI and CQS parameters. Specifically, the higher the $\mathrm{Sr}_{\mathrm{w}} \mathrm{F}_{\mathrm{x}} \mathrm{B}_{\mathrm{y}} \mathrm{O}_{\mathrm{z}}: \mathrm{Eu}^{2+}, \mathrm{Sm}^{2+}$ concentration results in the greater CRI and CQS, owning to the enriched red light components in the WLEDs. However, the flux has a tendency of dropping when $\mathrm{Sr}_{\mathrm{w}} \mathrm{F}_{\mathrm{x}} \mathrm{B}_{\mathrm{y}} \mathrm{O}_{\mathrm{z}}: \mathrm{Eu}^{2+}, \mathrm{Sm}^{2+}$ concentration rises excessively. This has been proved by using the Mie-scattering theory and the Lambert-Beer law. The results of this article are essential references for manufacturing WLEDs with higher chromatic quality.
\end{abstract}

Keywords: dual-layer remote phosphor geometry; WLEDs; Mie-scattering theory; color uniformity, luminous flux

\section{Introduction}

The fourth-generation light source named Phosphor Converted White Light Emitting Diodes (pcWLEDs) is used as an alternative to the conventional sources and has a variety of prospects in lighting solution [1-3]. Due to this reason, the white light-emitting diodes have become increasingly popular since they have been used commercially and residentially in many different fields of our daily life (backlighting, street illuminating, landscape, etc.) although their light extraction efficiency and the color uniformity of the white LED

*E-mail: nguyendoanquocanh@tdtu.edu.vn are the obstacles constantly confining their use [4]. Owning to the rapid rise of market demands, luminous efficiency and color quality really need further breakthrough to expand their applications [5]. One of the most common methods for white light generation is the combination of yellow rays converted from the red phosphors and the blue rays from the LED chip [6-8]. Although this concept might be recognizable, it must be accepted that the packaging design of LEDs and the organization of phosphor layers are vital to effectively determine the luminous efficiency, especially the color rendering index (CRI) [9-11]. Scientists have proposed several familiar phosphor coating methods for pcLED fabrication such as conformal and dispensing 
coating ones $[12,13]$. Nonetheless, these structures do not provide high color quality because of the degraded phosphors' light conversion caused by temperature increase at the interface between the yellow phosphors and the LED chips as this phosphor layer directly contacts the chip's surface. Therefore, it is essential to improve the efficiency of the phosphor material and prevent the phosphor from being damaged by reducing the effect of heat on it. According to the results of previous studies, the remote phosphor structure in which the phosphor and the heat source (LED chip) are far apart can reduce this effect [14]. With a sufficient distance of phosphor and the LED chip, it is easy for LEDs to be able to limit the light backscattering and circulating inside. This way is considered as an ideal solution to control the heating effects in LEDs, by which the LEDs can enhance their optical performances: the color quality and the luminous efficiency [15]. However, the remote phosphor design only meets the quality requirements of regular lighting applications while other illumination applications require higher performance, which means that the next LED generation needs to be created as an alternative of this remote phosphor structure. Up to now, some novel remote phosphor models have been proposed to increase the lumen efficiency as well as reduce the backscattering events where the phosphors scatter back to the LED chip. Another study showed that it is possible to redirect the light path from the chip to the LED surface and considerably reduce the light loss caused by internal reflection with an encapsulant of inverted cone lens and a surrounding ring remote phosphor layer [16]. A patterned remote phosphor packaging structure with an obvious zone in the perimeter area with no phosphor coating layer on the surrounding surface was reported to be capable of accomplishing a high angular color uniformity and stability [17]. Furthermore, with the patterned sapphire substrate in the remote design, the color uniformity in a far field pattern is much better than that in a conventional one $[18,19]$. As a result, a remote phosphor structure consisting of two phosphor layers, also known as dual-layer or double-layer remote phosphor structure, is proposed to improve the optical output for pc-LEDs. The aforementioned studies mainly refer to the ability to improve the color uniformity and luminescence generated by WLEDs of the remote phosphor structure. However, they only focus on WLEDs using single chip at low color temperatures. On the other hand, improving the optical quality for the high-colortemperature WLEDs confronts enormous obstacles.

In order to solve this issue, we proposed a double-layer remote phosphor structure to enhance the color quality of white-light LEDs at various correlated color temperatures (CCTs) from $5600 \mathrm{~K}$ to $8500 \mathrm{~K}$. The new idea presented in this paper is to use the red phosphor layer $\mathrm{Sr}_{\mathrm{w}} \mathrm{F}_{\mathrm{x}} \mathrm{B}_{\mathrm{y}} \mathrm{O}_{\mathrm{z}}: \mathrm{Eu}^{2+}, \mathrm{Sm}^{2+}$ to produce more red lights in WLEDs, resulting in higher CRI and color quality scale (CQS.) The paper also details $\mathrm{Sr}_{\mathrm{w}} \mathrm{F}_{\mathrm{x}} \mathrm{B}_{\mathrm{y}} \mathrm{O}_{\mathrm{z}}: \mathrm{Eu}^{2+}, \mathrm{Sm}^{2+}$ chemical composition and its great impact on the WLEDs' lighting output. The investigation figures out that the CRI and CQS achieve considerable improvement that is closely connected to the appearance of the added $\mathrm{Sr}_{\mathrm{w}} \mathrm{F}_{\mathrm{x}} \mathrm{B}_{\mathrm{y}} \mathrm{O}_{\mathrm{z}}$ : $\mathrm{Eu}^{2+}{ }_{,} \mathrm{Sm}^{2+}$ layer in the package. However, an appropriate amount of $\mathrm{Sr}_{\mathrm{w}} \mathrm{F}_{\mathrm{x}} \mathrm{B}_{\mathrm{y}} \mathrm{O}_{\mathrm{z}}: \mathrm{Eu}^{2+}, \mathrm{Sm}^{2+}$ concentration should be chosen to avoid a sharp decrease in the flux of reddish phosphor. Moreover, the additional red phosphor film located above the yellow YAG: $\mathrm{Ce}^{3+}$ phosphor layer results in two remarkable differences. First, the red-light spectrum of the emitted white light increases with the development of the red photons, which is one of the key factors in improving the chromatic performance. Second, the internal scattering and light transmission of WLEDs is inversely proportional to the concentration of $\mathrm{Sr}_{\mathrm{w}} \mathrm{F}_{\mathrm{x}} \mathrm{B}_{\mathrm{y}} \mathrm{O}_{\mathrm{z}}: \mathrm{Eu}^{2+}, \mathrm{Sm}^{2+}$. Thus, the choice of suitable concentration of $\mathrm{Sr}_{\mathrm{w}} \mathrm{F}_{\mathrm{x}} \mathrm{B}_{\mathrm{y}} \mathrm{O}_{\mathrm{z}}: \mathrm{Eu}^{2+}, \mathrm{Sm}^{2+}$ becomes very important for keeping the photosensitivity of WLEDs stable.

\section{Preparation and simulation}

\subsection{Material preparation}

Based on the ingredients of $\mathrm{Sr}_{\mathrm{w}} \mathrm{F}_{\mathrm{x}} \mathrm{B}_{\mathrm{y}} \mathrm{O}_{\mathrm{z}}: \mathrm{Eu}^{2+}, \mathrm{Sm}^{2+}$ listed in Table 1, the formula for calculation of this compound was 
drawn by calculating the molar percentage of each element [20]. Additionally, the fabrication process of $\mathrm{Sr}_{\mathrm{w}} \mathrm{F}_{\mathrm{x}} \mathrm{B}_{\mathrm{y}} \mathrm{O}_{\mathrm{z}}: \mathrm{Eu}^{2+}, \mathrm{Sm}^{2+}$ is also described in this part. Firstly, $\mathrm{Eu}_{2} \mathrm{O}_{3}$ and $\mathrm{Sm}_{2} \mathrm{O}_{3}$ in particle form are dissolved in a solution of dilute nitric acid. Simultaneously, $\mathrm{Sr}\left(\mathrm{NO}_{3}\right)_{2}$ and $\mathrm{H}_{3} \mathrm{BO}_{3}$ are also dissolved in warm water $\left(90{ }^{\circ} \mathrm{C}\right)$. These two solutions are mixed together, then a solution comprised of acetone and ammonium hydroxide with $1: 1$ ratio is added to this compound. The whole solution is stirred vigorously. After a while, a fine white precipitate is formed and turns into a slurry. Next, this slurry is kept at $80{ }^{\circ} \mathrm{C}$ for two hours, then it is cooled down to room temperature. For the next step, this precipitate is filtered and dried in the air and then blended with $\mathrm{SrF}_{2}$ and ground together. The resultant product is placed in an open quartz crucible and fired with an air flow at $900{ }^{\circ} \mathrm{C}$ for approximately an hour. After that, it is cooled down once again, then blended and ground into fine particles. The firing process goes on at $900{ }^{\circ} \mathrm{C}$ for two hours, but this time it is conducted in a flow of $\mathrm{H}_{2}$ in $\mathrm{N}_{2}$ gas through the same crucible. Finally, the resulted particles are cooled and re-ground.

\subsection{WLEDs modeling}

The LightTools 8.5.0 program and Mie-theory have been applied to simulate WLEDs with duallayer phosphor structure by analyzing the scattering of phosphor particles and assess the influence of $\mathrm{Sr}_{\mathrm{w}} \mathrm{F}_{\mathrm{x}} \mathrm{B}_{\mathrm{y}} \mathrm{O}_{\mathrm{z}}: \mathrm{Eu}^{2+}, \mathrm{Sm}^{2+}$ phosphor on the performance of the WLEDs at the high correlated temperatures, $5600 \mathrm{~K}$ to $8500 \mathrm{~K}$. The dual-layer remote phosphor configuration of WLEDs with a $\mathrm{Sr}_{\mathrm{w}} \mathrm{F}_{\mathrm{x}} \mathrm{B}_{\mathrm{y}} \mathrm{O}_{\mathrm{z}}: \mathrm{Eu}^{2+}, \mathrm{Sm}^{2+}$ layer on the YAG:Ce ${ }^{3+}$ phosphor-silicone compounding covering the LED chips, as shown in Fig. 1 was taken into considerations.

The simulated WLEDs model consists of four constituents: blue chips, a reflector cup, and two phosphor layers. These chips are bonded with a reflector at a depth of $2.07 \mathrm{~mm}$ in a cavity with a bottom length of $8 \mathrm{~mm}$, and a length of $9.85 \mathrm{~mm}$ at its top surface. The noticeable power of every blue chip is $1.16 \mathrm{~W}$ with a wavelength that peaks at $453 \mathrm{~nm}$. The refractive indices of $\mathrm{Sr}_{\mathrm{w}} \mathrm{F}_{\mathrm{x}} \mathrm{B}_{\mathrm{y}} \mathrm{O}_{\mathrm{z}}: \mathrm{Eu}^{2+}, \mathrm{Sm}^{2+}$ and YAG: $\mathrm{Ce}^{3+}$ phosphor particles are of 1.85 and 1.83 , respectively. To maintain a stable average CCTs, the phosphor concentration of YAG: $\mathrm{Ce}^{3+}$ needs modifications to be suitable with the concentration of $\mathrm{Sr}_{\mathrm{w}} \mathrm{F}_{\mathrm{x}} \mathrm{B}_{\mathrm{y}} \mathrm{O}_{\mathrm{z}}: \mathrm{Eu}^{2+}, \mathrm{Sm}^{2+}$.

\section{Results and discussion}

Fig. 2 shows the possible proportions between the red phosphor $\operatorname{Sr}_{\mathrm{w}} \mathrm{F}_{\mathrm{x}} \mathrm{B}_{\mathrm{y}} \mathrm{O}_{\mathrm{z}}: \mathrm{Eu}^{2+}, \mathrm{Sm}^{2+}$ concentration and the yellow phosphor $\mathrm{YAG}_{\mathrm{Ce}} \mathrm{Ce}^{3+}$ concentration to maintain the average CCTs and adjust the scattering and absorption characteristics of the two phosphor films in the package. This inevitably affects the quality of color and luminescence of WLEDs. Thus, an appropriate adjustment of $\mathrm{Sr}_{\mathrm{w}} \mathrm{F}_{\mathrm{x}} \mathrm{B}_{\mathrm{y}} \mathrm{O}_{\mathrm{z}}: \mathrm{Eu}^{2+}, \mathrm{Sm}^{2+}$ concentration plays a significant role in enhancing the color quality of WLEDs.

As $\mathrm{Sr}_{\mathrm{w}} \mathrm{F}_{\mathrm{x}} \mathrm{B}_{\mathrm{y}} \mathrm{O}_{\mathrm{z}}: \mathrm{Eu}^{2+}, \mathrm{Sm}^{2+}$ concentration increases from 2 wt. $\%$ to 26 wt. $\%$, YAG:Ce ${ }^{3+}$ concentration must decrease to keep the average CCTs constant. The same happens with different color temperatures of WLEDs, for instance, at $5600 \mathrm{~K}$, $6600 \mathrm{~K}, 7000 \mathrm{~K}, 7700 \mathrm{~K}$, or $8500 \mathrm{~K}$. The effect of red phosphor $\mathrm{Sr}_{\mathrm{w}} \mathrm{F}_{\mathrm{x}} \mathrm{B}_{\mathrm{y}} \mathrm{O}_{\mathrm{z}}$ : $\mathrm{Eu}^{2+}, \mathrm{Sm}^{2+}$ content on the emission spectra of WLEDs exhibited in the graphs in Fig. 3 to Fig. 7 is noticeable.

Depending on the requirements of manufacturers, the most suitable choice is to achieve the highest efficiency. If WLEDs with high color quality are requested, a small amount of luminescence can be reduced to meet the demand. In essence, white light is a collection of the spectral regions as shown in Fig. 3 to Fig. 7. These five figures represent the photosensitivity at different color temperatures, $5600 \mathrm{~K}, 6600 \mathrm{~K}, 7000 \mathrm{~K}, 7700 \mathrm{~K}$ and $8500 \mathrm{~K}$, respectively. As can be easily recognized, the spectrum of the red light from $648 \mathrm{~nm}$ to $738 \mathrm{~nm}$ tends to go up with the concentration of $\mathrm{Sr}_{\mathrm{w}} \mathrm{F}_{\mathrm{x}} \mathrm{B}_{\mathrm{y}} \mathrm{O}_{\mathrm{z}}: \mathrm{Eu}^{2+}, \mathrm{Sm}^{2+}$. However, this may be unimportant if the spectra in the two remaining regions ( $420 \mathrm{~nm}$ to $480 \mathrm{~nm}$ and $500 \mathrm{~nm}$ to $640 \mathrm{~nm}$ ) do not increase. The rise in the spectra of $420 \mathrm{~nm}$ to $480 \mathrm{~nm}$ increases the blue-light scattering. The 
Table 1. Composition of green-emitting $\mathrm{Sr}_{\mathrm{w}} \mathrm{F}_{\mathrm{x}} \mathrm{B}_{\mathrm{y}} \mathrm{O}_{\mathrm{z}}: \mathrm{Eu}^{2+}, \mathrm{Sm}^{2+}$ phosphor.

\begin{tabular}{lccccccc}
\hline Ingredient & $\begin{array}{c}\text { Mole } \\
{[\%]}\end{array}$ & $\begin{array}{c}\text { By weight } \\
{[\mathrm{g}]}\end{array}$ & $\begin{array}{c}\text { Molar mass } \\
{[\mathrm{g} / \mathrm{mol}]}\end{array}$ & $\begin{array}{c}\text { Mole } \\
{[\mathrm{mol}]}\end{array}$ & Ions & $\begin{array}{c}\text { Mole } \\
{[\mathrm{mol}]}\end{array}$ & $\begin{array}{c}\text { Mole } \\
{[\%]}\end{array}$ \\
\hline \hline $\mathrm{Sr}\left(\mathrm{NO}_{3}\right)_{2}$ & 10.09 & 126.98 & 211.63 & 0.6 & $\mathrm{Sr}^{2+}$ & 0.6 & 0.0241 \\
$\mathrm{SrF}_{2}$ & 5.43 & 40.58 & 125.62 & 0.32 & $\mathrm{~F}^{-}$ & 0.646 & 0.0259 \\
$\mathrm{H}_{3} \mathrm{BO}_{3}$ & 84.12 & 309.2 & 61.83 & 5 & $\mathrm{~B}^{3+}$ & 5 & 0.203 \\
$\mathrm{Eu}_{2} \mathrm{O}_{3}$ & 0.25 & 5.28 & 351.93 & 0.015 & $\mathrm{O}^{2-}$ & 18.665 & 0.748 \\
$\mathrm{Sm}_{2} \mathrm{O}_{3}$ & 0.11 & 2.09 & 348.72 & 0.006 & $\mathrm{Eu}^{2+}$ & 0.03 & 0.0012 \\
& \multicolumn{2}{c}{$\mathrm{Sr}_{\mathrm{w}} \mathrm{F}_{\mathrm{x}} \mathrm{B}_{\mathrm{y}} \mathrm{O}_{\mathrm{z}}: \mathrm{Eu}^{2+}, \mathrm{Sm}^{2+}$} & & $\mathrm{Sm}^{2+}$ & 0.012 & 0.00048 \\
\hline
\end{tabular}

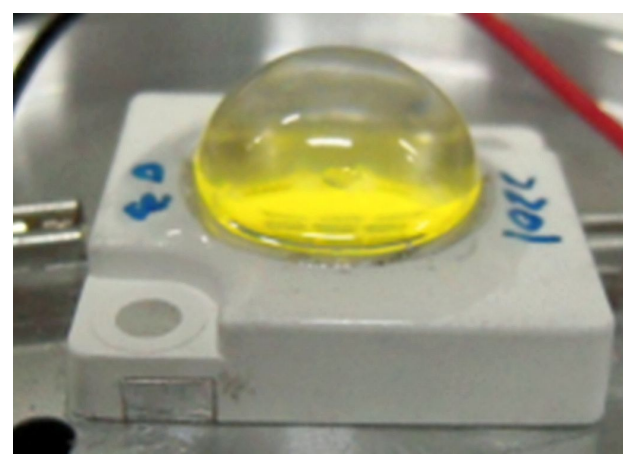

(a)

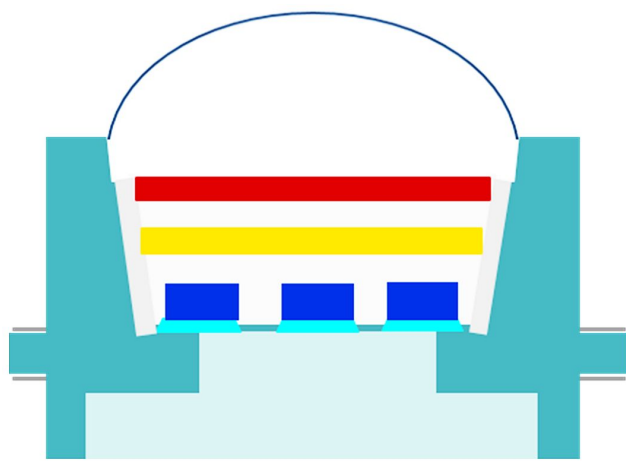

(c)

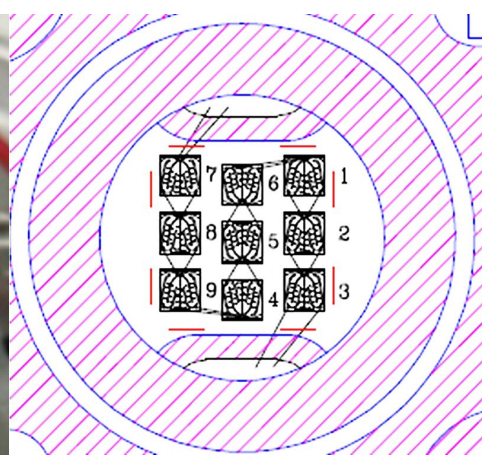

(b)

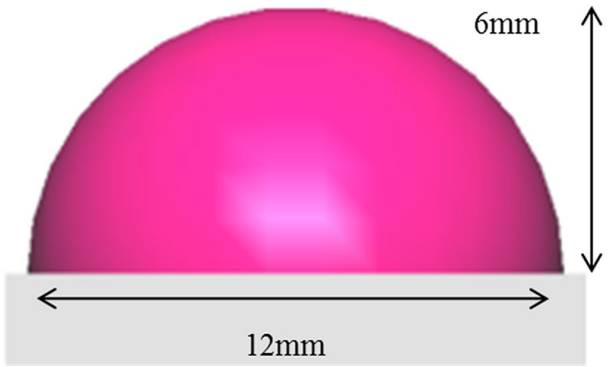

(d)

Fig. 1. Photograph of WLEDs structure: (a) actual WLEDs, (b) bonding diagram, (c) illustration of pc-WLEDs model: dual-layer remote phosphor structure with a red phosphor layer $\mathrm{Sr}_{\mathrm{w}} \mathrm{F}_{\mathrm{x}} \mathrm{B}_{\mathrm{y}} \mathrm{O}_{\mathrm{z}}: \mathrm{Eu}^{2+}, \mathrm{Sm}^{2+}$ above a yellow phosphor layer YAG:Ce ${ }^{3+}$, (d) simulation of WLEDs using LightTools commercial software.

higher is the color temperature, the higher is the emission spectrum. In other words, the color temperature and the spectrum are proportional to each other, leading to improved color and luminosity. As a result, the needs of manufacturers are totally met. This is a very practical result when applying the $\mathrm{Sr}_{\mathrm{w}} \mathrm{F}_{\mathrm{x}} \mathrm{B}_{\mathrm{y}} \mathrm{O}_{\mathrm{z}}: \mathrm{Eu}^{2+}, \mathrm{Sm}^{2+}$ to WLEDs, especially since controlling the color quality of WLEDs with high temperatures is a challenging issue. This study confirmed that $\mathrm{Sr}_{\mathrm{w}} \mathrm{F}_{\mathrm{x}} \mathrm{B}_{\mathrm{y}} \mathrm{O}_{\mathrm{z}}: \mathrm{Eu}^{2+}, \mathrm{Sm}^{2+}$ can completely improve the chromatic performance of WLEDs at either low or high color temperatures (5600 K or $8500 \mathrm{~K})$.

As shown in Fig. 8, the colorimetric index increases with the concentration of $\mathrm{Sr}_{\mathrm{w}} \mathrm{F}_{\mathrm{x}} \mathrm{B}_{\mathrm{y}} \mathrm{O}_{\mathrm{z}}: \mathrm{Eu}^{2+}, \mathrm{Sm}^{2+}$ at five selected CCTs, 


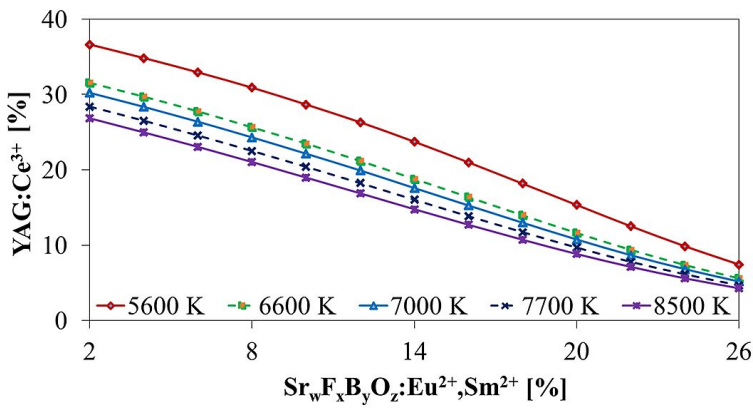

Fig. 2. The change of phosphor concentration for keeping the average CCTs.

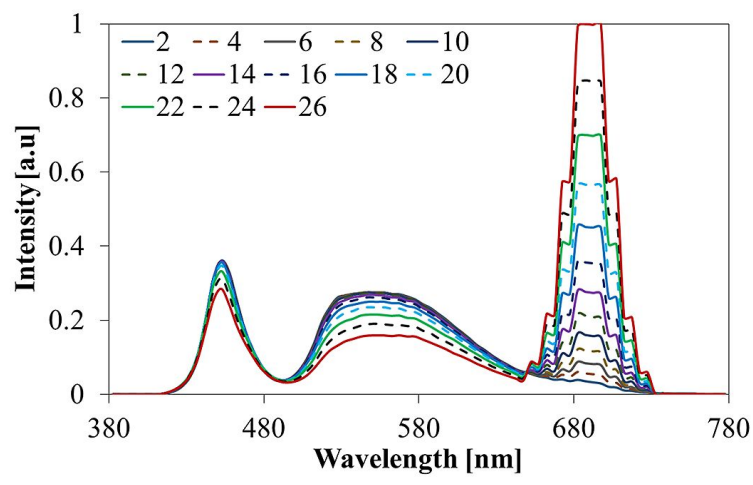

Fig. 3. The emission spectra of $5600 \mathrm{~K}$ WLEDs for different $\mathrm{Sr}_{\mathrm{w}} \mathrm{F}_{\mathrm{x}} \mathrm{B}_{\mathrm{y}} \mathrm{O}_{\mathrm{z}}: \mathrm{Eu}^{2+}, \mathrm{Sm}^{2+}$ concentrations.

which can be explained by the red-phosphor absorption property. When $\mathrm{Sr}_{\mathrm{w}} \mathrm{F}_{\mathrm{x}} \mathrm{B}_{\mathrm{y}} \mathrm{O}_{\mathrm{z}}: \mathrm{Eu}^{2+}, \mathrm{Sm}^{2+}$ absorbs the blue light generated by the LED chip, transforms it into the red one. Besides, not only is the blue light absorbed by this red phosphor material but also the yellow one. However, the

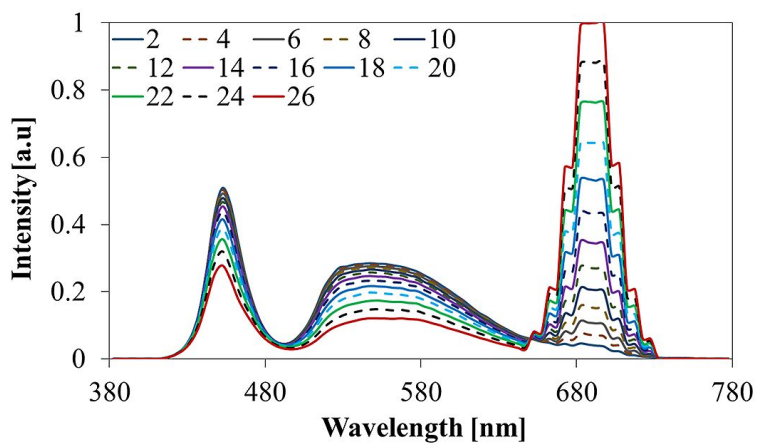

Fig. 4. The emission spectra of $6600 \mathrm{~K}$ WLEDs for different $\mathrm{Sr}_{\mathrm{w}} \mathrm{F}_{\mathrm{x}} \mathrm{B}_{\mathrm{y}} \mathrm{O}_{\mathrm{z}}: \mathrm{Eu}^{2+}, \mathrm{Sm}^{2+}$ concentrations.

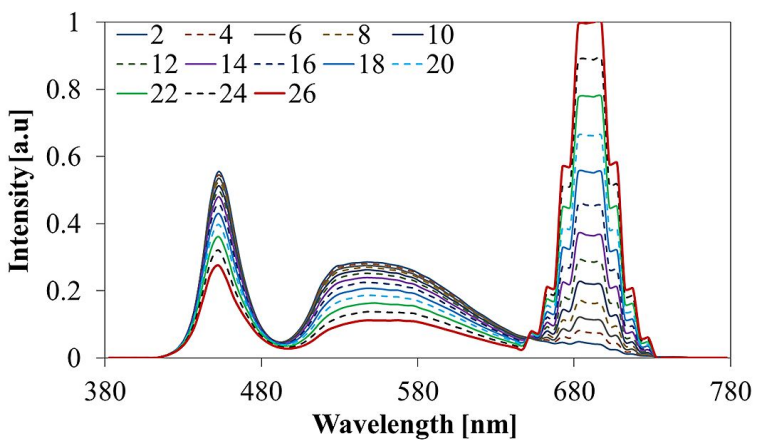

Fig. 5. The emission spectra of $7000 \mathrm{~K}$ WLEDs for different $\mathrm{Sr}_{\mathrm{w}} \mathrm{F}_{\mathrm{x}} \mathrm{B}_{\mathrm{y}} \mathrm{O}_{\mathrm{z}}: \mathrm{Eu}^{2+}, \mathrm{Sm}^{2+}$ concentrations.

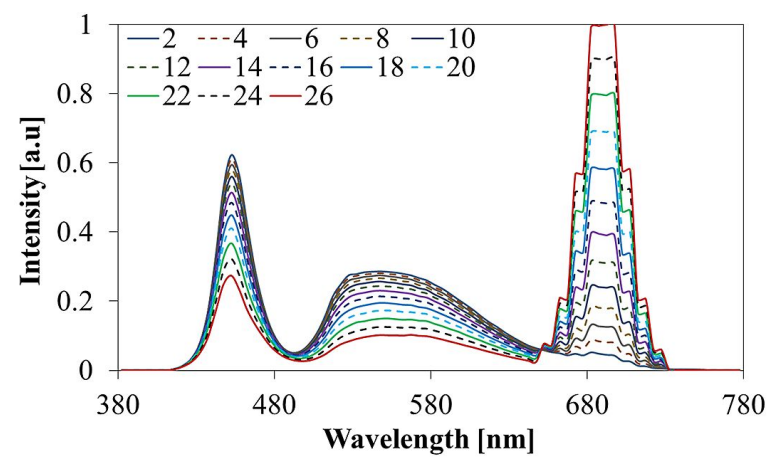

Fig. 6. The emission spectra of $7700 \mathrm{~K}$ WLEDs for different $\mathrm{Sr}_{\mathrm{w}} \mathrm{F}_{\mathrm{x}} \mathrm{B}_{\mathrm{y}} \mathrm{O}_{\mathrm{z}}: \mathrm{Eu}^{2+}, \mathrm{Sm}^{2+}$ concentrations.

ability to absorb the blue light is stronger than the ability to absorb the yellow light according to the absorption characteristics of the red phosphor particles. Hence, inside the LED package, the red light notably increases when $\mathrm{Sr}_{\mathrm{w}} \mathrm{F}_{\mathrm{x}} \mathrm{B}_{\mathrm{y}} \mathrm{O}_{\mathrm{z}}: \mathrm{Eu}^{2+}, \mathrm{Sm}^{2+}$ is added, leading to a higher CRI. Among the

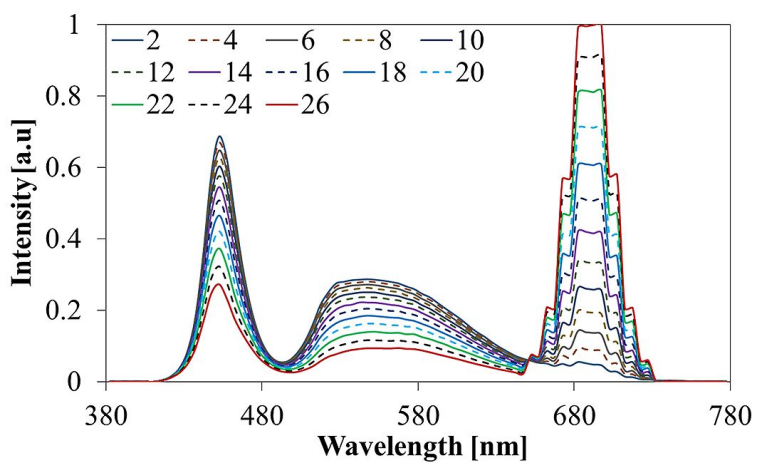

Fig. 7. The emission spectra of $8500 \mathrm{~K}$ WLEDs for different $\mathrm{Sr}_{\mathrm{w}} \mathrm{F}_{\mathrm{x}} \mathrm{B}_{\mathrm{y}} \mathrm{O}_{\mathrm{z}}: \mathrm{Eu}^{2+}, \mathrm{Sm}^{2+}$ concentrations. 


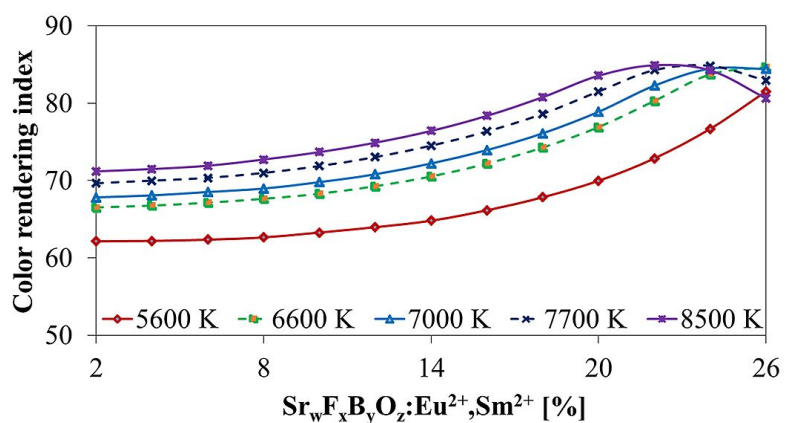

Fig. 8. The color rendering index of WLEDs as a function of $\mathrm{Sr}_{\mathrm{w}} \mathrm{F}_{\mathrm{x}} \mathrm{B}_{\mathrm{y}} \mathrm{O}_{\mathrm{z}}: \mathrm{Eu}^{2+}, \mathrm{Sm}^{2+}$ concentrations.

criteria of WLEDs quality, CRI is considered as one of the most important parameters. Although it is inevitable that the higher color rendering index comes with the increasing product cost, WLEDs with lower cost still can be produced using $\mathrm{Sr}_{\mathrm{w}} \mathrm{F}_{\mathrm{x}} \mathrm{B}_{\mathrm{y}} \mathrm{O}_{\mathrm{z}}: \mathrm{Eu}^{2+}, \mathrm{Sm}^{2+}$. However, this CRI is only a measure of the WLEDs' color quality. Just because a light source has a high CRI does not necessarily mean that it has the highest color quality. Therefore, this article provides an alternative to the CRI measurement called the color quality scale (CQS). CQS is a method used to evaluate different aspects of the objects' color quality illuminated by a light source. This metric involves three crucial factors of color quality, including the color rendering index, human preferences, and chromatic coordinates. Because of this, CQS is almost able to solve CRI's problems. Fig. 9 shows that CQS increases sharply with the concentration of $\mathrm{Sr}_{\mathrm{w}} \mathrm{F}_{\mathrm{x}} \mathrm{B}_{\mathrm{y}} \mathrm{O}_{\mathrm{z}}: \mathrm{Eu}^{2+}, \mathrm{Sm}^{2+}$ layer. Furthermore, when increasing the concentration of $\mathrm{Sr}_{\mathrm{w}} \mathrm{F}_{\mathrm{x}} \mathrm{B}_{\mathrm{y}} \mathrm{O}_{\mathrm{z}}: \mathrm{Eu}^{2+}, \mathrm{Sm}^{2+}$, the CQS is also improved remarkably.

Obviously, using the $\mathrm{Sr}_{\mathrm{w}} \mathrm{F}_{\mathrm{x}} \mathrm{B}_{\mathrm{y}} \mathrm{O}_{\mathrm{z}}: \mathrm{Eu}^{2+}, \mathrm{Sm}^{2+}$ can help dual-layer remote structure enhance the quality of white light for WLED devices. This is a highly significant result of this study, with the goal of enhancing the color quality. However, it is impossible to ignore the influence of $\mathrm{Sr}_{\mathrm{w}} \mathrm{F}_{\mathrm{x}} \mathrm{B}_{\mathrm{y}} \mathrm{O}_{\mathrm{z}}: \mathrm{Eu}^{2+}, \mathrm{Sm}^{2+}$ on the output of the flux.

The following paragraphs will focus on the mathematical expressions used to calculate the performance of various types WLEDs. The calculation

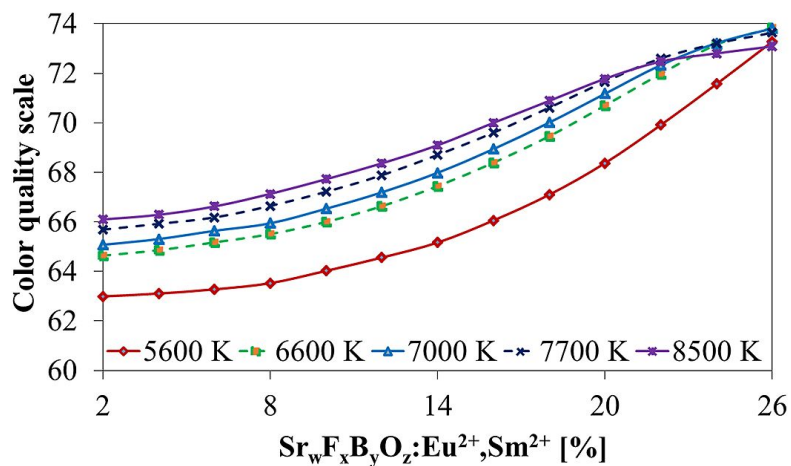

Fig. 9. The color quality scale of WLEDs as a function of $\mathrm{Sr}_{\mathrm{w}} \mathrm{F}_{\mathrm{x}} \mathrm{B}_{\mathrm{y}} \mathrm{O}_{\mathrm{z}}: \mathrm{Eu}^{2+}{ }_{,} \mathrm{Sm}^{2+}$ concentrations.

of the transmitted blue light and converted yellow light for a single-layer remote phosphor configuration having the phosphorus thickness of $2 \mathrm{~h}$ can be expressed as:

$$
\begin{gathered}
P B_{1}=P B_{0} \times e^{-2 \alpha_{B 1} h} \\
P Y_{1}=\frac{1}{2} \frac{\beta_{1} \times P B_{0}}{\alpha_{B 1}-\alpha_{Y 1}}\left(e^{-2 \alpha_{Y 1} h}-e^{-2 \alpha_{B 1} h}\right)
\end{gathered}
$$

For the transmitted blue light and converted yellow light of the dual-layer package whose phosphor layers have the thickness of $h$, the formulas are:

$$
\begin{gathered}
P B_{2}=P B_{0} \times e^{-2 \alpha_{B 2} h} \\
P Y_{2}=\frac{1}{2} \frac{\beta_{2} \times P B_{0}}{\alpha_{B 2}-\alpha_{Y 2}}\left(e^{-2 \alpha_{Y 2} h}-e^{-2 \alpha_{B 2} h}\right)
\end{gathered}
$$

$h$ in these equations is the thickness of each phosphor layer in a WLED package. The subscript 1 indicates the single-layer remote phosphor structure, while 2 describes a dual-layer one. $\beta$ is the mathematic symbol of the conversion coefficient for blue light converting to yellow light; and $\gamma$ means the yellow light reflection coefficient. The light intensity from the blue LED is defined by the intensities of blue light (PB) and yellow light (PY), and this parameter is expressed as $\mathrm{PB}_{0} . \alpha_{\mathrm{B}}$ and $\alpha_{\mathrm{Y}}$ are parameters describing the fractional energy loss of the blue and yellow lights in their process of propagation in the phosphor layer.

The WLEDs' illumination effectiveness is improved significantly with the dual-layer remote 
phosphor model in comparison with the result from the single-layer design:

$$
\frac{\left(P B_{2}+P Y_{2}\right)-\left(P B_{1}+P Y_{1}\right)}{P B_{1}+P Y_{1}}>0
$$

The scattering of $\mathrm{Sr}_{\mathrm{w}} \mathrm{F}_{\mathrm{x}} \mathrm{B}_{\mathrm{y}} \mathrm{O}_{\mathrm{z}}: \mathrm{Eu}^{2+}, \mathrm{Sm}^{2+}$ particles and the scattering cross-section $\mathrm{C}_{\text {sca }}$ for spherical particles are examined and computed with Miescattering theory. Simultaneously, the LambertBeer law is applied to calculate the transmitted light power:

$$
I=I_{0} \exp \left(-\mu_{e x t} L\right)
$$

$\mathrm{I}_{0}$ indicates the incident light power, $\mathrm{L}$ demonstrates the thickness of the phosphor film, and $\mu_{\text {ext }}$ presents the extinction coefficient. In addition, the extinction coefficient can be computed by: $\mu_{\mathrm{ext}}=\mathrm{N}_{\mathrm{r}} \cdot \mathrm{C}_{\mathrm{ext}}$, in which $\mathrm{N}_{\mathrm{r}}$ shows the number density distribution of phosphor particles $\left(\mathrm{mm}^{-3}\right)$, and $\mathrm{C}_{\text {ext }}\left(\mathrm{mm}^{2}\right)$ refers to the extinction cross-section of phosphor particles.

Obviously, equation 5 demonstrates the larger lighting output of WLEDs packaged with duallayer remote structure, compared to the efficiency resulting from the single-layer structure. Therefore, this research paper has confirmed that with the double-layer remote phosphor design, WLED devices can attain effective optical output. However, the flux of the double-layer remote phosphor is significantly affected by the amount of $\mathrm{Sr}_{\mathrm{w}} \mathrm{F}_{\mathrm{x}} \mathrm{B}_{\mathrm{y}} \mathrm{O}_{\mathrm{z}}: \mathrm{Eu}^{2+}, \mathrm{Sm}^{2+}$. Obviously, based on the Lambert-Beer law, the $\mu_{\text {ext }}$ parameter is directly proportional to $\mathrm{Sr}_{\mathrm{w}} \mathrm{F}_{\mathrm{x}} \mathrm{B}_{\mathrm{y}} \mathrm{O}_{\mathrm{z}}: \mathrm{Eu}^{2+}, \mathrm{Sm}^{2+}$ concentration but inversely proportional to the energy of light. Thus, as the two phosphor layers get their thickness fixed, the emitted flux could be attenuated even though $\mathrm{Sr}_{\mathrm{w}} \mathrm{F}_{\mathrm{x}} \mathrm{B}_{\mathrm{y}} \mathrm{O}_{\mathrm{z}}$ : $\mathrm{Eu}^{2+}, \mathrm{Sm}^{2+}$ concentration rises.

Fig. 10 illustrates the downward trend of the lumen flux in all five considered CCTs. With 26 wt.\% concentration of $\mathrm{Sr}_{\mathrm{w}} \mathrm{F}_{\mathrm{x}} \mathrm{B}_{\mathrm{y}} \mathrm{O}_{\mathrm{z}}: \mathrm{Eu}^{2+}, \mathrm{Sm}^{2+}$, there is a clear decline in the flux. Nevertheless, the advantages of the red phosphor layer $\mathrm{Sr}_{\mathrm{w}} \mathrm{F}_{\mathrm{x}} \mathrm{B}_{\mathrm{y}} \mathrm{O}_{\mathrm{z}}: \mathrm{Eu}^{2+}, \mathrm{Sm}^{2+}$ including improved CRI and CQS make this material worth considering. Besides that, the luminous output from the dual-layer

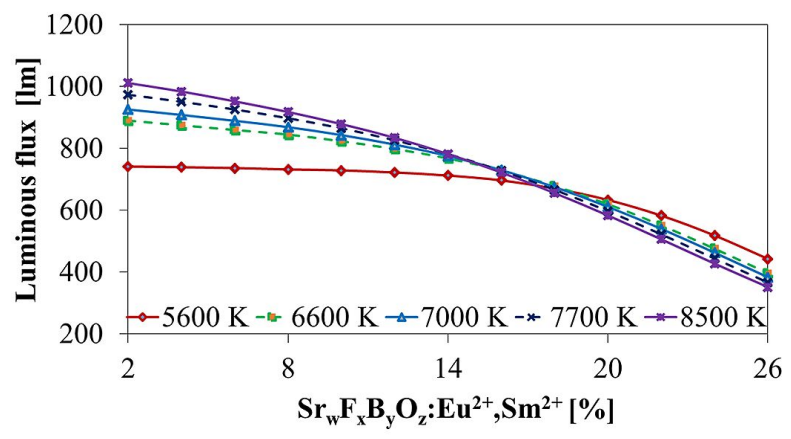

Fig. 10. The luminous flux of WLEDs as a function of $\mathrm{Sr}_{\mathrm{w}} \mathrm{F}_{\mathrm{x}} \mathrm{B}_{\mathrm{y}} \mathrm{O}_{\mathrm{z}}: \mathrm{Eu}^{2+}, \mathrm{Sm}^{2+}$ concentrations.

structure is better than that of the single-layer package (not using the red phosphor layer); and hence, this luminescence reduction is totally acceptable. It depends on manufacturer's intentions to make a suitable selection of $\mathrm{Sr}_{\mathrm{w}} \mathrm{F}_{\mathrm{x}} \mathrm{B}_{\mathrm{y}} \mathrm{O}_{\mathrm{z}}: \mathrm{Eu}^{2+}, \mathrm{Sm}^{2+}$ when producing this batch WLEDs.

\section{Conclusions}

In short, the article presents how $\mathrm{Sr}_{\mathrm{w}} \mathrm{F}_{\mathrm{x}} \mathrm{B}_{\mathrm{y}} \mathrm{O}_{\mathrm{z}}: \mathrm{Eu}^{2+}, \mathrm{Sm}^{2+}$ affects CRI and CQS of the dual-layer phosphor WLED model. Using the Mie-scattering theory and the Lambert-Beer's law, this paper has proven that $\mathrm{Sr}_{\mathrm{w}} \mathrm{F}_{\mathrm{x}} \mathrm{B}_{\mathrm{y}} \mathrm{O}_{\mathrm{z}}: \mathrm{Eu}^{2+}, \mathrm{Sm}^{2+}$ is a good choice for improving color quality. The red phosphor can be applied for WLEDs having either low $(5600 \mathrm{~K})$ or high $(8500 \mathrm{~K})$ color temperature to enhance the chromatic performance. In this study, we have dealt with a very challenging task for remote phosphor structures to enhance the white light performance. However, a small drawback related to the luminous emission still exists since as the concentration of $\mathrm{Sr}_{\mathrm{w}} \mathrm{F}_{\mathrm{x}} \mathrm{B}_{\mathrm{y}} \mathrm{O}_{\mathrm{z}}: \mathrm{Eu}^{2+}, \mathrm{Sm}^{2+}$ increases excessively, the luminosity decreases dramatically. As a result, it is essential to determine an appropriate concentration of this red phosphor after considering the manufacturers' requirements. The article has provided a lot of practical information for reference in producing better color quality WLED lamps.

\section{Acknowledgements}

This research is funded by the Foundation for Science and Technology Development of Ton Duc Thang University 
(FOSTECT), website: http: //f ostect.tdtu.edu.vn, under the Grant FOSTECT.2017.BR.06.

\section{References}

[1] Tang Q., Qiu K., Li J., Zhang W., Zeng Y., J. Mater. Sci.: Mater. Electron., 28 (2017), 18686.

[2] Jin L., Du X., Lei X. Ren L., Feng Y., Chen W., Appl. Phys. A, 114 (2014), 631.

[3] Di X., He X., Jiang J., Li P., Xiang W., Liang X., Shen T., J. Mater. Sci.: Mater. Electron., 28 (2017), 8611.

[4] Son K.H., JEON Y.M., OH M.M., Hortic. Environ. Biotechnol., 57 (2016), 560.

[5] Chiu Z.W., Hsiao Y.J., Fang T.H., Ji L.W., J. SolGel Sci. Technol., 69 (2014), 299.

[6] Xue H., Zhu Y., Ge M., J. Mater. Sci.: Mater. Electron., 28 (2017), 9032.

[7] Meng Y., Zhao W. Chen., J. Appl. Phys. A, 122 (2016), 636.

[8] Chen D.C., LIU Q.L., Rare Met., 33 (2014), 203.

[9] Chen D.C., Song Z., Liu Z.G., Deng Z.H., Wu L., CAO Y.G., LIU Q.L., Rare Met., 33 (2014), 80.

[10] Shen X., Zhang D.F., Fan X.W., Hu G.S., Bian X.B., YAng L., J. Mater. Sci.: Mater. Electron., 27 (2016), 976.

[11] Game D.N., Ingale N.B., Omanwar S.K., J. Mater. Sci.: Mater. Electron., 28 (2017), 915.
[12] Manwar Y.P., Palaspagar R.S., Sonekar R.P., OMANWAR S.K., J. Mater. Sci.: Mater. Electron., 28 (2017), 994.

[13] Chen D.C., Liu Z.G., Deng Z.H., Wang C., CaO Y.G., LIU Q.L., Rare Met., 33 (2014), 348.

[14] Xin S., Zhou F., Wang C., Li Z., YuAn S., Zhu G., J. Mater. Sci.: Mater. Electron., 28 (2017), 19134.

[15] Gao X., Lei L., Yin Y., Xie J., Wang Y., Gu W., Russ. J. Phys. Chem., 88 (2014), 1232.

[16] Zhang W., Yin X., LiU Y., Zhang N., ZhaO G., Hou J., Fang Y., J. Mater. Sci.: Mater. Electron., 27 (2016), 5357.

[17] Zhou L., Huang J., Mo F., Mater. Sci.-Poland, 32 (2014), 88.

[18] Rajesh D., Ratnakaram Y.C., Naidu M.D., Indian. J. Phys., 88 (2014), 1291.

[19] BAJAJ N.S., KoparkaR K.A., NAgPuRE P.A. OMANWAR S.K., J. Opt., 46 (2017), 91.

[20] Yen W.M., Weber M.J., Inorganic Phosphors: Compositions, Preparation and Optical Properties, CRC Press, LLC, 2000 N.W. Corporate Blvd., Boca Raton Florida 33431, 2004. 